\title{
Valuación del capital intelectual, su contabilización y presentación como activo intangible en los estados financieros
}

\section{Valuation of intellectual capital, its accounting and presentation as an intangible asset in the financial statements}

Víctor Samuel, Quiroz Juárez

Universidad Nacional de Cañete, Perú

Judith Soledad, Yangali Vicente

Universidad Cesar Vallejo; Perú

Autor para correspondencia: samquiroz3@ hotmail.com, judithsyv@gmail.com

Fecha de recepción: 30 de agosto de 2018 - Fecha de aceptación: 01 noviembre de 2018

Resumen: El objetivo de la investigación fue determinar las metodologías aplicadas en la valuación del capital intelectual, la contabilización y presentación como activo intangible en las empresas de servicios. El tipo de investigación es de orientación básica, también llamada fundamental o pura. La ejecución del proyecto de investigación se realizó a través de la aplicación del método analítico, comparativo y explicativo. El diseño de investigación es no experimental, de corte transversal. La población está conformada por todas aquellas empresas, cuya sede principal se encuentran en Lima Metropolitana, que tienen como actividad principal la prestación de servicio, que fue un total de 1,150,987 empresas. El diseño de la muestra es Muestreo aleatorio simple. El tamaño de muestra es igual a 384 empresas. La técnica utilizada fue la encuesta, el instrumento utilizado fue el cuestionario. La investigación ha permitido constatar el valor estratégico del capital intelectual en las empresas y el papel que cumplen los recursos intangibles como medio para obtener una ventaja competitiva y por lo tanto conseguir resultados empresariales superiores. Se ha podido verificar que existe consenso en cuanto a los componentes del capital intelectual: capital humano, capital estructural y capital relacional. Se concluye precisando que la valuación del capital intelectual genera valor para las empresas, mediante el reconocimiento, contabilización y presentación como activo intangible en los estados financieros.

Palabras claves: capital intelectual; contabilización; empresas de servicios

Abstract: The objective of the research was to determine the methodologies applied in the valuation of intellectual capital, the accounting and presentation as an intangible asset in service companies. The type of research is basic orientation, also called fundamental or pure. The execution of the research project was carried out through the application of the analytical, comparative and explanatory method. The research design is non-experimental, cross-sectional. The population is made up of all those companies, whose main headquarters are in Metropolitan Lima, whose main activity is service provision, which was a total of 1,150,987 companies. The design of the sample is simple random sampling. The sample size is equal to 384 companies. The technique used was the survey, the instrument used was the questionnaire. Research has made it possible to verify the strategic value of intellectual capital in companies and the role of intangible resources as a means to obtain a competitive advantage and therefore achieve superior business results. It has been verified that there is consensus regarding the components of intellectual capital: 
human capital, structural capital and relational capital. It concludes by stating that the valuation of intellectual capital generates value for companies, through recognition, accounting and presentation as an intangible asset in the financial statements.

Key words: intellectual capital; accounting; service companies

\section{Introducción}

\section{Planteamiento del problema}

En la actualidad las mejores empresas del mundo emplean la tecnología de punta para sus sistemas de información y ya no se circunscriben únicamente a las empresas de las industrias pesadas y manufactureras que dependen de materia primas agotables como el petróleo o los minerales; sino que ahora la economía se desarrolla en la orientación del conocimiento como soporte para el despegue de las empresas, como de los países que apliquen este importante factor del desarrollo humano. El éxito de las empresas se encuentra en su capital intelectual. La capacidad para gestionar el intelecto humano es prioritaria para convertirse en una empresa creativa, eficiente y competitiva en el mercado actual. El capital intelectual representa la parte intangible de las empresas, tales como la capacidad de las empresas para aprender y adaptarse a nuevas tendencias de la economía del mercado, el entrenamiento de los empleados y la capacidad de respuesta a los requerimientos de los clientes; implica también el liderazgo en tecnología. En términos generales consiste en la generación de valor para la empresa.

Sin embargo, no es sencillo poder determinar cuál es el valor que aporta el capital intelectual en las empresas; porque para esto se debería medir y resulta complicado medir aspectos como la capacidad de innovación, la lealtad de los clientes, el ingenio de los empleados para la solución de problemas, la creación de nuevos software, etc. La contabilidad tradicional no tiene los instrumentos necesarios para medir estos aspectos; la información que brindan los estados financieros sobre los activos intangibles es parcial, figuran en el balance por un valor que no refleja su potencial económico, esto demuestra que los modelos contables actuales no están preparados para reflejar razonablemente su valor, afectando económica y financieramente a las empresas al momento de determinar su valor real. En este sentido la investigación se dirigió a la obtención documentada de los aportes de varios autores que han estudiado el Capital Intelectual, su importancia y como puede medirse contablemente. Surgen, entonces algunas interrogantes relacionadas con este importante tema, las que planteo a continuación:

\section{Problema General:}

¿En qué medida las metodologías aplicadas en la valuación del capital intelectual, influye en su contabilización y presentación como activo intangible en las empresas de servicios?

\section{Problemas Específicos:}

$\checkmark \quad$ ¿En qué medida los Recursos Humanos ven reflejadas sus competencias en las empresas de servicios?

$\checkmark \quad$ ¿De qué manera en los Derechos de Propiedad Intelectual en las empresas de servicios se incluyen los sistemas de información?

$\checkmark$ ¿Cómo las buenas relaciones de las empresas de servicios con sus clientes influyen para la formación alianzas estratégicas? 


\section{Justificación}

Las empresas modernas pasan por un periodo de transición a medida que se vuelven más dependientes de su conocimiento interno y el procesamiento de la información para ser más competitivos; el valor de sus activos intangibles se vuelven superiores al de sus activos fijos. En los últimos años, diferentes investigadores y estudiosos del Capital Intelectual tratan de establecer una medición de este importante factor estratégico de las empresas, generándose diversos métodos para su valuación; convencidos de que el valor de lo intangible es lo que agrega valor a la organización, más allá del valor de los bienes de capital y productos manufacturados. El éxito de las empresas, de aquellas que aspiran a ser más competitivas en el mercado, se encuentra precisamente en el capital intelectual, en la gestión del talento de sus trabajadores, en su capacidad de creatividad, de innovación, en la eficacia de sus management, el carácter de sus relaciones con los clientes y en general con el entorno donde se desempeñan. La investigación se reforzará los conocimientos sobre el Capital Intelectual, su valuación y presentación como activo intangible en los estados financieros. Espero, además, que sirva de orientación para que las empresas intenten valuar eficazmente el Capital Intelectual con el que cuentan, o en todo caso crearlo para generar un nuevo valor en las mismas.

\section{Objetivo General:}

\section{Objetivos}

Determinar las metodologías aplicadas en la valuación del Capital intelectual, la contabilización y presentación como activo intangible en las empresas de servicios.

\section{Objetivos Específicos:}

$\checkmark$ Determinar en cuánto los Recursos Humanos ven reflejadas sus competencias en las empresas de servicios.

$\checkmark$ Precisar si en los Derecho de Propiedad Intelectual de las empresas de servicios se incluyen los sistemas de información.

$\checkmark$ Evaluar si las buenas relaciones en las empresas de servicios con sus clientes influyen en la formación alianzas estratégicas.

\section{Marco Referencial}

\section{Modelos de medición de capital intelectual.}

Actualmente, el valor de una empresa depende menos de sus activos fijos y financieros (valores), es decir, el valor que presentan sus libros o la suma del valor real de sus activos menos sus pasivos; ahora dependen más de sus "activos intangibles" que normalmente nunca vienen recogidos ni valorados en sus estados financieros. Los recursos intangibles suelen pasar desapercibidos debido a la dificultad que presenta su identificación y valoración, pues por lo general no aparecen en los estados contables y además suelen presentar problemas de apropiabilidad, pues en muchos casos los derechos de propiedad no están bien definidos. En el entorno actual, son los valores de carácter intangible los que proporcionan fuertes ventajas competitivas y los que diferencian unas empresas de otras. Entre dichos valores podríamos 
señalar, el know-how, la experiencia, motivación lealtad del personal de la empresa; las tecnologías y conocimientos disponibles que permitan la fabricación de productos y que puedan concretarse en patentes, diseños y bases de datos; la organización interna, el prestigio, la imagen de la empresa, la red comercial, la vinculación con los clientes y proveedores, etc., En este entorno, la información contable tradicional, no refleja adecuadamente todos los activos de la empresa y, por lo tanto, el auténtico valor de la misma. Realizar la valuación del capital intelectual no es una tarea fácil, considerando que existen diferentes modelos o herramientas de medición y por ende se pueden llegar a valoraciones diferentes en una misma empresa, dependiendo de la importancia que se les da a cada factor. Por otra parte, si el objetivo de la presente investigación es determinar las metodologías aplicadas en la valoración del capital intelectual, resulta pertinente una revisión de los modelos más relevantes utilizados en las organizaciones.

\section{Cuadro de Mando Integral - CMI (Balanced Scorecard- BSC).}

Kaplan y Norton (1993) propusieron un modelo de gestión empresarial, basado en la estrategia, cuyo funcionamiento exigía la definición de una serie de indicadores que permitieran la toma de decisiones. La idea fundamental que subyace en él, es que sólo puede gestionarse aquello que puede medirse.

El BSC es una herramienta revolucionaria para movilizar a la gente hacia el pleno cumplimiento de la misión a través de canalizar las energías, habilidades y conocimientos específicos de la gente en la organización hacia el logro de metas estratégicas de largo plazo. Permite tanto guiar el desempeño actual como apuntar al desempeño futuro.

Este modelo presenta un conjunto equilibrado de indicadores que representan la visión y la estrategia de la empresa medidas en cuatro perspectivas: - desempeño financiero, conocimiento del cliente, procesos internos de negocios y, aprendizaje y crecimiento- para alinear iniciativas individuales, organizacionales y trans - departamentales e identifica procesos enteramente nuevos para cumplir con objetivos del cliente y accionistas. El BSC es un robusto sistema de aprendizaje para probar, obtener realimentación y actualizar la estrategia de la organización. Provee el sistema gerencial para que las compañías inviertan en el largo plazo en clientes, empleados, desarrollo de nuevos productos y sistemas más bien que en gerenciar la última línea para bombear utilidades de corto plazo. Cambia la manera en que se mide y maneja un negocio.

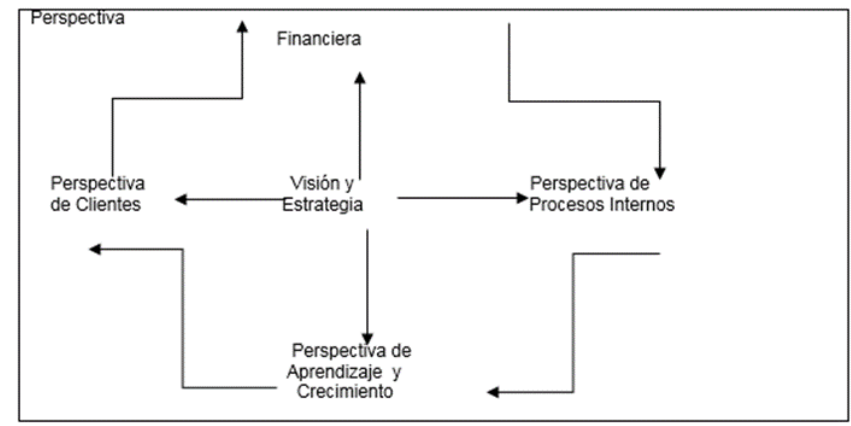

La Figura 1. Muestra la estructura del Cuadro de Mando Integral y las interrelaciones de las distintas perspectivas, con la visión y la estrategia de la empresa. 
El CMI sugiere que veamos a la organización desde cuatro perspectivas, cada una de las cuales debe responder a una pregunta determinada:

$\checkmark$ Desarrollo y Aprendizaje (Learning and Growth): ¿Podemos continuar mejorando y creando valor?

$\checkmark$ Interna del Negocio (Internal Business): ¿En qué debemos sobresalir

$\checkmark$ Del cliente (Customer): ¿Cómo nos ven los clientes?

$\checkmark$ Financiera (Financial): ¿Cómo nos vemos a los ojos de los accionistas?

\section{Navegador de Skandia (Edvinson, 1997)}

Este modelo tiene su origen en la compañía de seguros Skandia. El autor distingue entre capital humano y capital estructural - compuesto por el capital organizativo y capital cliente- El modelo se estructura en base a "enfoques", resultando el enfoque humano el principal centro de atención, sobre el cual giran los otros.

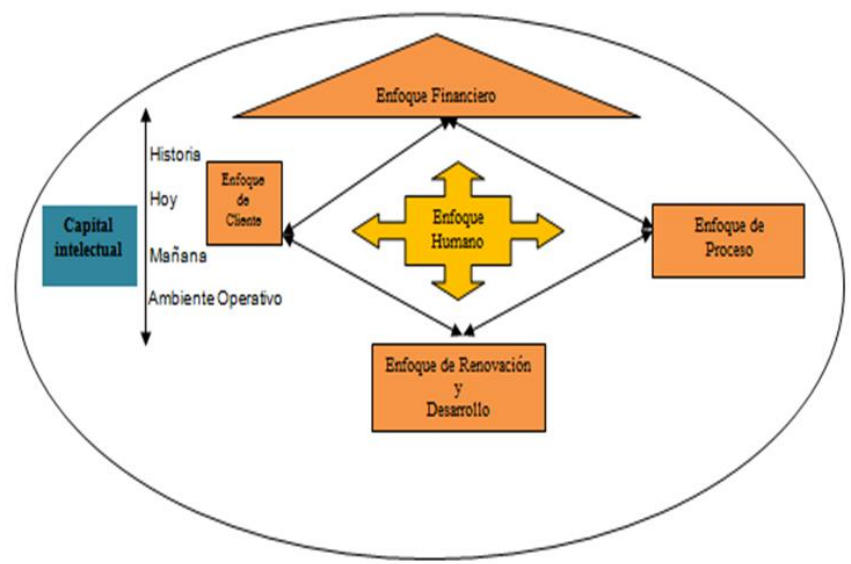

Figura 2. Navegador de Skandia Fuente: Edvinsson (1997: 371)

En el modelo se puede notar claramente la presencia de la variable tiempo. El pasado (historia) está definido por el enfoque financiero; el presente (hoy) definidos por los clientes y los procesos y el futuro (mañana) considera el enfoque de renovación y desarrollo

\section{Monitor de los Activos Intangibles (Sveiby, 1997)}

El modelo planteado por este autor, se basó en indicadores que agrupo en tres bloques que permitirían la medición y gestión de los activos intangibles en las empresas.

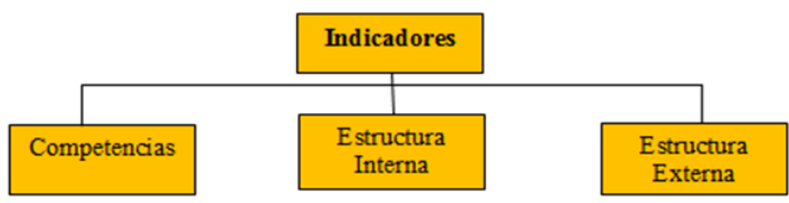

Figura 3. Monitor de los Activos Intangibles Fuente: Sveiby (1997: 12) 
Las competencias se refieren a la capacidad de las personas para actuar den distintas situaciones, incluye sus habilidades, educación, experiencia, valores, etc. El autor sostiene que las personas son el verdadero agente de los negocios, pues la acción humana es la que da como resultado la producción física como lo intangible. Las competencias son inherentes al ser humano, aunque pueden ser controladas por las empresas.

La estructura interna, se encuentra compuesta por los modelos y sistemas administrativos e informáticos de la empresa, la cultura organizacional. Como puede notarse los componentes de la estructura interna constituyen propiedad de la empresa.

La estructura externa está constituida por las relaciones con los clientes y proveedores, también están incluidas las marcas y la reputación de la empresa.

El Balance invisible, es un concepto que en base al argumento de Sveiby (1997), y podemos observarlo en la Figura 4.

\begin{tabular}{|c|c|c|}
\hline \multirow{4}{*}{$\bigwedge$ Balance Visible } & Activo Tangibles & Financiación Visible \\
\hline & Inmovilizado Material & Capital \\
\hline & $\begin{array}{l}\text { Realizable } \\
\text { (Deudores + Existencias) }\end{array}$ & Deuda a Largo Plazo \\
\hline & Disponible & Deuda a Corto Plazo \\
\hline \multirow{4}{*}{$\bigwedge$ Balance Invisible } & Estructura Interna & \multirow{2}{*}{ Capital Invisible } \\
\hline & Estructura Externa & \\
\hline & Competencias personas & Compromisos \\
\hline & Activos Intangibles & Financiación Invisible \\
\hline
\end{tabular}

Figura 4. Balance Invisible Fuente: Sveiby (1997)

Se puede apreciar que el balance tradicional no recoge elementos intangibles que influyen en el valor de una empresa y sus perspectivas de crecimiento. Estos activos "no contabilizados" suponen en promedio, varias veces el valor de los activos tangible.

Para la medición de los activos intangible Sveiby, propone tres tipos de indicadores:

- Indicadores de crecimiento e innovación: Recogen el potencial futuro de la empresa

- Indicadores de eficiencia: informan el grado de productividad de los activos

- Indicadores de estabilidad: Indican el grado de permanencia de estos activos en la empresa.

Tabla 1. Monitor de Activos Intangibles

\begin{tabular}{llll}
\hline $\begin{array}{l}\text { Grupo de } \\
\text { Indicadores }\end{array}$ & Competencias & Estructura Interna & Estructura Externa \\
\hline
\end{tabular}




\begin{tabular}{|c|c|c|c|c|c|}
\hline $\begin{array}{l}\text { Crecimiento } \\
\text { e Innovación }\end{array}$ & $\begin{array}{ll} & \text { Experiencia } \\
& \text { Nivel de } \\
& \text { educación } \\
> & \text { Coste de } \\
\text { formación }\end{array}$ & $>$ & $\begin{array}{l}\text { Inversiones } \\
\text { en nuevos } \\
\text { métodos y } \\
\text { sistemas. } \\
\text { Inversiones } \\
\text { en los } \\
\text { sistemas de } \\
\text { información } \\
\text { Contribución } \\
\text { de los } \\
\text { clientes a la } \\
\text { estructura } \\
\text { externa }\end{array}$ & $>$ & $\begin{array}{l}\text { Rentabilidad } \\
\text { por cliente } \\
\text { Crecimiento } \\
\text { Orgánico }\end{array}$ \\
\hline Eficiencia & $\begin{array}{l}\text { Proporción } \\
\text { de } \\
\text { profesionales } \\
>\quad \begin{array}{l}\text { Valor } \\
\text { añadido por } \\
\text { profesional }\end{array}\end{array}$ & $>$ & $\begin{array}{l}\text { Proporción } \\
\text { del personal } \\
\text { de apoyo } \\
\text { Ventas por } \\
\text { personal de } \\
\text { apoyo } \\
\text { Medidas de } \\
\text { valores y } \\
\text { actitudes }\end{array}$ & $>$ & $\begin{array}{l}\text { Índice de } \\
\text { satisfacción } \\
\text { de los } \\
\text { clientes } \\
\text { Índice } \\
\text { Éxito/Fracaso } \\
\text { Ventas por } \\
\text { clientes }\end{array}$ \\
\hline Estabilidad & 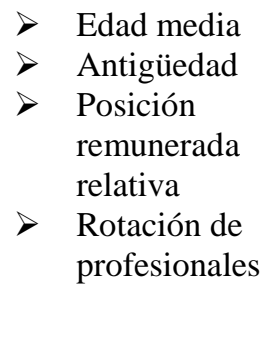 & 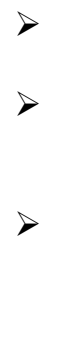 & $\begin{array}{l}\text { Edad de la } \\
\text { Organización } \\
\text { Rotación del } \\
\text { personal de } \\
\text { apoyo } \\
\text { El ratio } \\
\text { rookie }\end{array}$ & $>$ & $\begin{array}{l}\text { Proporción } \\
\text { de grandes } \\
\text { clientes } \\
\text { Ratios de } \\
\text { clientes fieles } \\
\text { Estructura de } \\
\text { antigüedad } \\
\text { Frecuencia } \\
\text { de repetición. }\end{array}$ \\
\hline
\end{tabular}

Fuente: www.gestiondelconocimiento.com/doc. (1999)

\section{Technology Broker (Brooking, 1997)}

Este modelo considerando que el valor de mercado de las empresas es la suma de los actives tangibles más el Capital Intelectual; parte del mismo concepto que el modelo Skandia.

Para que la contabilidad tradicional valore las empresas, tanto los valores materiales e inmateriales deben tener un precio o valor de mercado. Pero en ningún caso valora la empresa como organización, ni las capacidades, aptitudes, actitudes de los activos intangibles.

Brooking considera la siguiente taxonomía de activos (ver figura 5): De mercado, humanos, de propiedad intelectual y de infraestructura

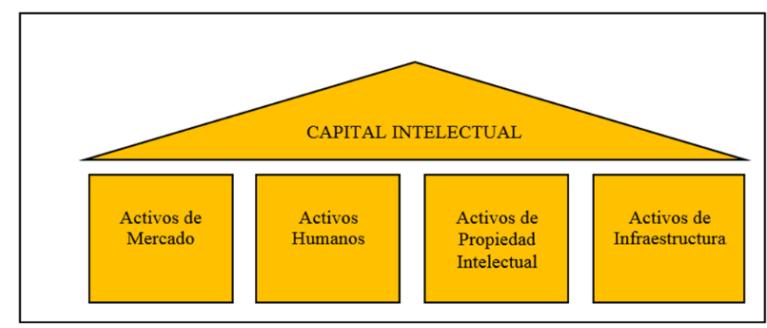


Figura 5. Technology Broker-Fuente: Brooking (1996)

Los activos de Mercado, son aquellos bienes inmateriales que guardan relación con el mercado; son la causa que algunas empresas sean adquiridas en ocasiones por importes superiores a su valor contable. Sus indicadores son: marcas, clientes, nombre de la empresa, cartera de pedidos, canales de distribución, capacidad de colaboración.

Los activos humanos, relieva la importancia que tienen las personas en las empresas por su capacidad de aprender y utilizar el conocimiento. Incluye: la pericia colectiva, la capacidad creativa, la habilidad para resolver problemas, el liderazgo, capacidad de gestión, Negociación, estilo de pensamiento.

Los activos de propiedad intelectual, son los derechos de propiedad que provienen del intelecto. Otorgan un valor adicional que supone para la empresa la exclusividad de La explotación de un activo intangible. Sus indicadores son: Patentes, Copyright, derecho de diseño, secretos de fabricación.

Los activos de infraestructura, se refiere a las tecnologías, metodologías y procesos que hacen posible el funcionamiento de la organización. En este grupo se encuentran: la cultura de la organización, sistemas de información, base de datos, métodos de dirección, sistemas de comunicación.

\section{Modelo Knowdedge Value Added (KVA) (2008)}

El modelo de Valor Agregado del Conocimiento (KVA) creado por Thomas Housel y Valery Kanevsky, es un marco de trabajo para medir el valor de los activos del conocimiento corporativo. La razón de la aceptación creciente del KVA como una herramienta de medición válida, radica en sus fundamentos teóricos acertados, su practicidad, y su facilidad de uso por parte de las empresas que involucran el conocimiento como lo plantean los autores.

El KVA se fundamenta en el principio de que el valor que se genera en la empresa está directamente relacionado con el conocimiento requerido para producir los resultados de cada proceso. Los recursos de la empresa tienen conocimiento que debe ser utilizado para producir los resultados de los procesos. Se sustenta en el hecho de que la habilidad de la empresa para generar una ganancia no recae únicamente en la distribución efectiva de los costos y una valoración de los mismos, sino que recae también en la habilidad de la organización para convertir su conocimiento en parte del valor agregado a su producto final.

Si se considera que en todo proceso una entrada (imput) se convierte en una salida (ouput o producción), y esta salida posee un valor considerablemente mayor con respecto a la entrada, podemos afirmar que el cambio efectuado sobre la entrada en el proceso genera valor y que para efectuar ese cambio se requiere un cierto grado de conocimiento sobre las características de la entrada y del proceso; por lo tanto el conocimiento genera valor (Housel y Boll, 2001).

El índice fundamental del modelo es el Retorno del Conocimiento (Return on Knowledge- ROK), se calcula a través de una relación donde el numerador representa el porcentaje de los ingresos o ventas (unidades monetarias) que se asigna a la cantidad de 
conocimiento necesario para completar un determinado proceso con éxito, en proporción a la cantidad total del conocimiento requerido para generar todas las salidas de la empresa. El denominador del índice es el costo de ejecutar el proceso.

Tabla 2. Pasos para implementar la Metodología KVA

\begin{tabular}{|c|c|c|c|}
\hline Pasos & Tiempo de Aprendizaje & Descripción del Proceso & $\begin{array}{l}\text { Método binario de } \\
\text { consulta }\end{array}$ \\
\hline Uno & \multicolumn{3}{|c|}{ Identificar el proceso principal y sus subprocesos } \\
\hline Dos & $\begin{array}{l}\text { Establecer unidades } \\
\text { comunes y niveles de } \\
\text { complejidad para medir } \\
\text { el tiempo de aprendizaje }\end{array}$ & $\begin{array}{l}\text { Describe los procesos en } \\
\text { términos de las instrucciones } \\
\text { requeridas para reproducirlas } \\
\text { y seleccionar unidades de } \\
\text { descripción del proceso. }\end{array}$ & $\begin{array}{l}\text { Crea un conjunto de } \\
\text { preguntas binarias. Si o } \\
\text { No, tales que todas las } \\
\text { posibles salidas son } \\
\text { representadas como una } \\
\text { consecuencia de respuestas } \\
\text { Si o No }\end{array}$ \\
\hline Tres & $\begin{array}{l}\text { Calcular el tiempo de } \\
\text { aprendizaje para ejecutar } \\
\text { cada subproceso }\end{array}$ & $\begin{array}{l}\text { Calcula el número de } \\
\text { palabras de descripción de } \\
\text { proceso (actividades) } \\
\text { páginas en manual, y líneas } \\
\text { de código pertenecientes a } \\
\text { cada subproceso }\end{array}$ & $\begin{array}{l}\text { Calcula la longitud de la } \\
\text { secuencia de respuestas Si } \\
\text { o No para cada } \\
\text { subproducto. }\end{array}$ \\
\hline Cuatro & \multicolumn{3}{|c|}{$\begin{array}{l}\text { Designar un periodo de muestreo lo suficientemente largo para capturar una muestra } \\
\text { representativa del producto final del proceso o de la producción (ouput) del servicio. }\end{array}$} \\
\hline Cinco & $\begin{array}{l}\text { Multiplicar el tiempo de } \\
\text { aprendizaje para cada } \\
\text { subproceso por el } \\
\text { número de veces que el } \\
\text { subproceso se ejecuta } \\
\text { durante el periodo de } \\
\text { muestra. }\end{array}$ & $\begin{array}{l}\text { Multiplicar el número de } \\
\text { palabras de proceso usado } \\
\text { para describir cada } \\
\text { subproceso por el número de } \\
\text { veces que el subproceso se } \\
\text { ejecuta durante el periodo de } \\
\text { muestra }\end{array}$ & $\begin{array}{l}\text { Multiplicar la longitud de } \\
\text { la cadena de Si o No, para } \\
\text { cada subproceso, por el } \\
\text { número de veces que el } \\
\text { subproceso se ejecuta } \\
\text { durante el periodo de } \\
\text { muestreo. }\end{array}$ \\
\hline Sexto & \multicolumn{3}{|c|}{$\begin{array}{l}\text { Calcular el costo para ejecutar Conocimiento (tiempo de aprendizaje e instrucciones } \\
\text { del proceso) para determinar el costo del proceso. }\end{array}$} \\
\hline Séptimo & \multicolumn{3}{|c|}{ Calcular el ROK y el ROP e interpretar el resultado. } \\
\hline
\end{tabular}

\section{Valor Económico Agregado - EVA. (Economic Value Added).}

Fue desarrollado por Stern Stewart. Es una medida de desempeño financiero que combina el ingreso residual con los principios de las finanzas corporativas modernas, específicamente que todo capital tiene un costo y que las ganancias, más que el costo de capital, crean ganancias para los accionistas.

El EVA o ganancia económica es la diferencia entre la utilidad operativa después de impuestos que una empresa obtiene y la mínima que debería obtenerse. O dicho de otra manera, es la cantidad que resulta de restar a utilidad operativa antes de impuestos el costo financiero que implica la posesión de los activos por parte de la empresa

El EVA también puede entenderse desde la perspectiva de la rentabilidad. Si una empresa obtiene sobre sus activos netos de operación una rentabilidad superior a su costo de capital significa que sobre el valor de dichos activos, se genera un remanente. Este remanente es el EVA que se define como, por lo tanto, como el remanente que generan los activos netos de operación cuando rinden por encima del costo de capital Puede calcularse con la siguiente expresión 


\section{EVA = UOADI (Activos netos de operación * Costo de capital)}

Es un indicador que puede aplicarse tanto al conjunto de empresas como a cualquiera de sus partes, como por ejemplo, unidades de negocios, divisiones, filiales, etc.

La utilización del EVA, conjuntamente con el cuadro de mando integral, permite identificar las relaciones causa-efecto que existen entre los principales factores claves del éxito en la empresa. Estas relaciones empiezan por las perspectivas de los recursos humanos y terminan por la perspectiva de los procesos. Estas perspectivas determinan como ven los clientes a la empresa y la capacidad para generar utilidades y gestionar los activos más eficientemente y con costos de capital menores.

Tabla 3. Tipología del Capital Intelectual

\begin{tabular}{|c|c|c|c|c|c|}
\hline Modelos/Autores & Capital Humano & \multicolumn{2}{|c|}{ Capital estructural } & \multicolumn{2}{|c|}{$\begin{array}{l}\text { Capital } \\
\text { Relacional }\end{array}$} \\
\hline $\begin{array}{l}\text { Cuadro de Mando } \\
\text { Integral (Kaplan y } \\
\text { Norton, 1993) }\end{array}$ & $\begin{array}{l}\text { Perspectiva de } \\
\text { Aprendizaje y } \\
\text { Crecimiento }\end{array}$ & \multicolumn{2}{|c|}{$\begin{array}{l}\text { Perspectiva de Procesos } \\
\text { Internos }\end{array}$} & \multicolumn{2}{|c|}{$\begin{array}{l}\text { Perspectiva de } \\
\text { clientes }\end{array}$} \\
\hline $\begin{array}{l}\text { Navegador de } \\
\text { Skandia (Edvisson, } \\
\text { 1997) }\end{array}$ & Enfoque Humano & \multicolumn{2}{|c|}{ Enfoque de Procesos } & \multicolumn{2}{|c|}{$\begin{array}{l}\text { Enfoque de } \\
\text { Cliente }\end{array}$} \\
\hline $\begin{array}{l}\text { Monitor de los } \\
\text { Activos Intangibles } \\
\text { (Sveiby, 1997) }\end{array}$ & Competencias & \multicolumn{2}{|c|}{ Estructura Interna } & \multicolumn{2}{|c|}{$\begin{array}{l}\text { Estructura } \\
\text { Externa }\end{array}$} \\
\hline $\begin{array}{l}\text { Intelect } \\
\text { (Euroforum, 1998) }\end{array}$ & Capital Humano & \multicolumn{2}{|c|}{ Capital Estructural } & \multicolumn{2}{|c|}{ Capital Relacional } \\
\hline $\begin{array}{l}\text { Intellectus (CIC, } \\
\text { 2003) }\end{array}$ & Capital Humano & $\begin{array}{l}\text { Capital } \\
\text { Tecnológic } \\
\text { o }\end{array}$ & $\begin{array}{l}\text { Capital } \\
\text { Organizativo }\end{array}$ & $\begin{array}{l}\text { Capital } \\
\text { de } \\
\text { Negocio }\end{array}$ & $\begin{array}{l}\text { Capit } \\
\text { al } \\
\text { Socia } \\
1\end{array}$ \\
\hline $\begin{array}{l}\text { Chen, Zhu, y Yuan, } \\
2004\end{array}$ & Capital Humano & $\begin{array}{l}\text { Capital } \\
\text { Innovación }\end{array}$ & $\begin{array}{l}\text { Capital } \\
\text { Estructural }\end{array}$ & \multicolumn{2}{|c|}{ Capital Cliente } \\
\hline $\begin{array}{l}\text { Bueno, Salvador y } \\
\text { Rodriguez, } 2004\end{array}$ & Capital Humano & $\begin{array}{l}\text { Capital } \\
\text { Tecnológic } \\
\text { o }\end{array}$ & $\begin{array}{l}\text { Capital } \\
\text { Organizativo }\end{array}$ & $\begin{array}{l}\text { Capital } \\
\text { de } \\
\text { Negocio }\end{array}$ & $\begin{array}{l}\text { Capit } \\
\text { al } \\
\text { Socia } \\
1\end{array}$ \\
\hline $\begin{array}{l}\text { Guthrie, Petty, } \\
\text { Yongvanich, } 2004\end{array}$ & Capital Humano & \multicolumn{2}{|c|}{ Capital Interno } & \multicolumn{2}{|c|}{ Capital Externo } \\
\hline $\begin{array}{l}\text { Ordoñez Pablo, } \\
2004\end{array}$ & Capital Humano & \multicolumn{2}{|c|}{$\begin{array}{l}\text { Capital Estructural: Capital } \\
\text { Tecnológico y Capital } \\
\text { Organizativo. }\end{array}$} & \multirow{2}{*}{\multicolumn{2}{|c|}{ Capital Relacional }} \\
\hline Joia, 2004 & Capital Humano & \multicolumn{2}{|c|}{$\begin{array}{l}\text { Capital Estructural: Capital } \\
\text { Interno, Capital Externo y } \\
\text { Capital Innovación }\end{array}$} & & \\
\hline
\end{tabular}

Fuente: elaboración propia

El primer componente se refiere a las personas y casi la totalidad de los casos se le denomina capital humano, excepto Kaplan y Norton, 1993, que le denomina perspectiva de 
aprendizaje y crecimiento. El segundo componente está vinculado a los procesos, estructura interna y externa, a la tecnología e innovación, algunos autores separan el aspecto tecnológico del organizativo (Intellectus, 2003, Bueno, 2004, Chen, 2004). El tercer componente está referido a la relación de la empresa con el cliente y las distintas denominaciones se pueden observar en la tabla.

\section{Definición de términos básicos}

En este apartado trataremos de dar a conocer los distintos conceptos sobre el capital intelectual, las variables, las dimensiones y los indicadores que comprende esta investigación.

\section{Capital intelectual.}

Bradley (1997) sostiene que el capital Intelectual consiste en la habilidad para transformar el conocimiento y los activos intangibles en recurso que creen riqueza, tanto en empresas como en países.

Para Sveiby (1997) el capital intelectual ayuda a explicar la diferencia entre el valor de mercado y el valor en libros de la empresa, porque el capital intelectual no se incluye en las cuentas financieras. Considera que las empresas dirigen sus esfuerzos en dos direcciones: hacia dentro de la organización construyendo la estructura interna y hacia afuera trabajando con los clientes. El valor total de mercado de la empresa está formado por el patrimonio visible tangible más tres tipos de activos intangibles: la organización, los clientes y las personas, de modo que el valor de mercado de la empores se puede interpretar como un reflejo directo del balance invisible.

Steward (1997) define el Capital Intelectual como conocimiento, información, propiedad intelectual, experiencia que puede utilizarse para crear valor. Es fuerza cerebral colectiva. Es difícil de identificar y aún más de distribuir eficazmente, pero quien la encuentra y la explota, triunfa.

Según Eoroforum, (1998) se define como el conjunto de conocimiento, habilidades, destrezas y experiencias que las personas emplean en el trabajo que desempeñan, siendo el valor, ventaja competitiva y éxito organizacional.

Bontis (1998) menciona que este capital hace parte de la estrategia de administración del conocimiento y lo define como "relación de causalidad entre Capital Humano, capital Relacional y Organizativo"

Lev (2001) argumenta que los recursos intangibles son aquellos que pueden generar valor en el futuro, pero que, sin embargo, no tienen cuerpo físico o financiero y sostiene que el Capital Intelectual" representa las relaciones principales, generadoras de activos intangibles, entre innovación, practicas organizativas y recursos humanos.

Según el autor Leif Edvinsson (2003), el capital intelectual "es la posesión de conocimientos, experiencia aplicada, tecnología organizacional, relaciones con clientes y 
destrezas profesionales, que dan a una empresa una ventaja competitiva en el mercado". Su definición la explica mediante una interesante metáfora: Una corporación es como un árbol. Hay una parte que es visible: el tronco, las ramas y las hojas (Estados financieros, organigramas, folletos) y una parte que está oculta: las raíces. Si solamente el dueño del árbol se preocupa en buscar fruta madura para cosechar, el árbol puede morir. Para que le árbol crezca y continúe dando buenos frutos, será necesario que las raíces estén sanas y nutridas (el Capital Intelectual). Esto es válido para las empresas; si se ignoran los valores ocultos, la empresa no subsistirá en el largo plazo. Sostiene que el capital intelectual es como un iceberg. Por encima se ven los recursos financieros, físicos, visibles bajo el sol y por debajo hay algo invisible, mucho más grande.

Bueno (2005) intenta integrar el concepto: “Acumulación de conocimiento que crea valor o riqueza cognitiva poseída por una organización, compuesta por un conjunto de activos intangibles (intelectuales o recurso y capacidades basadas en conocimiento que cuando se ponen en acción, según determinada estrategia, en combinación con el capital físico o tangible, es capaz de producir bienes y servicios y de generar ventajas competitivas o competencias esenciales en el mercado para la organización".

Botero (2007) lo define como un activo identificable de naturaleza no monetaria y sin sustancia física, que la organización requiere como materia prima fundamental para la producción o suministro de bienes o servicios; se materializa en el conocimiento de todo tipo que poseen sus integrantes.

La mayoría de autores coinciden en que el Capital Intelectual está conformado por tres elementos que se pueden observar en la figura 6.

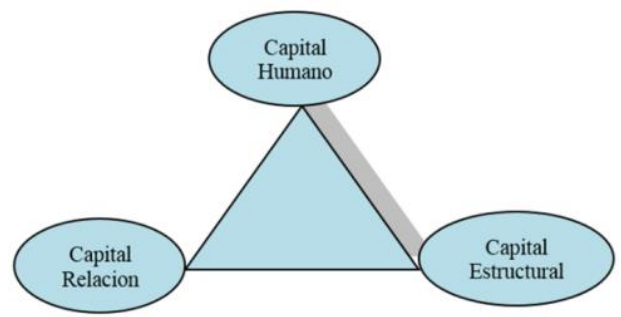

Figura 6. Elementos del Capital Intelectual Fuente: elaboración propia

Como elemento de gestión empresarial, el capital intelectual es objeto de mediciones, con indicadores adecuados para sus componentes con lo cual es posible gestionarlo adecuadamente, lo que lo convierte en una herramienta estratégica para incrementar el valor y la competitividad de las organizaciones.

\section{Capital Humano.}

Conjunto de conocimientos, destrezas, inventivas y capacidad de los empleados para la ejecución de una tarea que son de su responsabilidad. La compañía no es propietaria del capital humano. (Edvinsson y Steward, 1998, p.55). 
Abraham Maslow le atribuye mucha importancia a la satisfacción de las necesidades como condición para el desarrollo psicológico; sin embargo indica que en ciertas personas creativas, el impulso por crear parece ser más importante que cualquier otra necesidad; están dispuestas a pasar grandes privaciones para poder expresar su talento creativo.

Porras en su obra "El factor humano en la empresa" acerca de qué se puede hacer para que las normas que desarrollan los grupos sean más coherentes con sus empresas, señala algunas pautas: 1) Mostrar una mayor consideración hacia los empleados desde el momento de su incorporación; los grupos cuyo supervisor expresa consideración tienden a desarrollar normas favorables a la organización; 2) Dar una mayor participación a los empleados en las decisiones que les afectan; de este modo, éstos se sienten menos independientes.

\section{Capital Estructural.}

Se refiere al valor que usualmente no se refleja en los sistemas de contabilidad y que es el resultado de los sistemas o servicios que una organización ha constituido. (Edvinsson y Steward, 1998, p.55). Está determinado por la información tácita como las normas, programas, base de datos, patentes, configuración de marcas, métodos y procedimientos de trabajo, modelos, manuales, sistemas de dirección y gestión.

Una organización es, "la coordinación planificada de las actividades de un conjunto de personas para el logro de un objetivo común y explícito, a través de una cierta división del trabajo y de una jerarquía de autoridad y de responsabilidad". Distingue los siguientes elementos dentro de las empresas:

a) Coordinación de actividades.

b) Objetivos comunes.

c) División del trabajo.

d) Jerarquía de autoridad.

e) Normas y procedimientos.

f) Incentivos y sanciones.

\section{Capital Relacional.}

Es el resultado de las relaciones que una empresa ha construido con sus clientes. (Edvinsson y Steward, 1998, p.55). Surge por el intercambio de información con externos, son las relaciones de la organización con los agentes de su entorno, a los acuerdos de cooperación y alianzas estratégicas, tecnológicas, de producción y comerciales, a conceptualización de las marcas, medios de comunicación y a la imagen de la empresa,

\section{Valuación del capital intelectual.}

En la llamada sociedad del conocimiento, que hoy ha de ser considerada ya como una realidad incuestionable, los activos y recursos intangibles tienen un peso específico cada día más importante, aun cuando raramente aparecen reflejados o aparecen deficientemente valorados en los libros de contabilidad, a pesar de ser, casi siempre, un factor clave de éxito porque en ellos 
suele basarse la ventaja competitiva por la vía de la diferenciación, de la calidad del servicio y, en muchos casos, de la eficiencia en costes.

En definitiva, la gestión de un conjunto de activos intangibles se está convirtiendo en uno de los principales pilares de las organizaciones al encontrarse inmersas en una economía soportada en el conocimiento. Esto es, la era industrial está siendo reemplazada por la sociedad de la información y del conocimiento. De esta forma, los conocimientos y la información son ahora los nuevos instrumentos de poder. Las organizaciones y empresas deben tener una noción mucho más profunda de la evolución de su ambiente elaborando útiles de gestión más eficaces, deben saber cómo medir los conocimientos, cómo crearlos y cómo convertirlos en valor. Así, las organizaciones necesitan nuevos útiles de gestión.

\section{Contabilización y presentación del capital intelectual en los Estados Financieros.}

La crítica que se le hace a la contabilidad tradicional es que se organiza alrededor del costo histórico, sin tener en cuenta que el mundo cambió hacia una percepción futura (prospectiva) y del entorno (mercados). Se realizaron esfuerzos para mejorar la información histórica ajustándola, re-expresándola y actualizándola; el problema no se solucionó dado que la contabilidad se expresa en la moneda funcional, y ésta se encuentra siempre sujeta a cambios muchas veces abruptos por efectos de la inflación, devaluación, recesión, etc. Por lo que se puede afirmar que, la posición financiera ya no es suficiente. El valor razonable emerge como una alternativa urgente.

Actualmente se tiene conciencia que las empresa no son entes aislados en el mundo de los negocios. Por ello se insiste en que los estados financieros de la empresa de alguna manera tienen que reflejar la relación de ésta en el contexto en que se mueve

Mantilla (2004), sostiene que existen tres propuestas principales:

- Que los estados financieros incluyan las cuentas ambientales

- Que los estados financieros comprendan dos partes, una financiera y otra ambiental.

- Que existan separados los estados financieros y los estados ambientales.

Se discute mucho sobre la relación con otros componentes de la gestión empresarial como la competitividad, la posición en el mercado, liderazgo empresarial. Lo que sí está claro es que los estados financieros tradicionales deben forzosamente que cambiar, que reflejen claramente la situación real del negocio, es decir que muestre no solamente la posición financiera sino también sobre su desempeño financiero. El más importante de los cambios radica en modificar el énfasis en el registro contable por un énfasis en la medición del valor de la empresa. Esto es lo que significa la contabilidad del conocimiento, como una respuesta a los desafíos provenientes de los activos intangibles. Se espera que dentro de poco se tengan nuevos estados financieros en condiciones de armonización contable y comparabilidad global.

\section{Metodología}

El tipo de investigación es de orientación básica, también llamada fundamental o pura cuyo objetivo será la de contribuir a la ampliar los conocimientos, presentando las diferentes 
teorías que tratan sobre el tema de capital intelectual. El enfoque es cuantitativo, el diseño utilizado es el no experimental, nivel comparativo y el corte es transversal.

La ejecución del proyecto de investigación se realizó a través de la aplicación de los métodos de investigación que a continuación se indican: El método analítico, porque consistió en la separación del todo en las partes: la valuación del capital intelectual y su contabilización y presentación como activo intangible. El método comparativo, se aplicó con la finalidad de poder contrastar los informes obtenidos con la realidad actual, es decir que comparamos las distintas metodologías de valuación del capital intelectual que aplican cada una de las empresas investigadas. También se empleó el método explicativo con el propósito de comprobar las relaciones de las variables y de esta manera contrastar las hipótesis

Diseño de la investigación, constituye el plan general del investigador para obtener respuestas a sus interrogantes o comprobar la hipótesis de investigación. El diseño de investigación desglosa las estrategias básicas que el investigador adopta para generar información exacta e interpretable. El diseño no experimental, se considera en el sentido de que no se pretende modificar la realidad sino que se estableció criterios y diseñó modelos, estrategias y lineamientos para la aplicación de un modelo de valuación del capital intelectual de una empresa. El corte es transversal o transaccional consiste en la recolección de datos. El propósito de este diseño es describir las variables y analizar su incidencia e interrelación en el tiempo y su perspectiva en el futuro de la empresa.

\section{Población.}

Población Objetivo: La población está conformada por todas aquellas empresas, cuya sede principal se encuentran en Lima Metropolitana, que tienen como actividad principal la prestación de servicios.

\section{Determinación del tamaño de la población:}

Para la determinación del tamaño de la población se ha tomado como fuente el Directorio Central de Empresas del INEI, el cual actualizado al año 2010, cuenta con un total de 1,150,987 empresas. Dentro de los rubros de clasificación del sector económico de la actividad principal de las empresas, hemos considerado aquellos relacionados a la prestación de servicios que incluyen: Agencias de Viaje, Centros Educativos No Estatales, Establecimientos de Hospedaje, Servicios Eléctricos, Transportes y Comunicaciones, Universidades, Restaurantes y Servicios en General, lo que suma un total de 419,903 empresas a nivel nacional. De estas empresas el $48.30 \%$ (202,814 aproximadamente), corresponden a Lima Metropolitana. Luego el tamaño poblacional objetivo asciende a 202,814 empresas.

\section{Muestra}

Diseño de la muestra: Muestreo aleatorio simple.

Error muestral: Error de +/- 3\%

Nivel de Confianza: Nivel de confianza del $95 \%$ 
Tamaño de la muestra: El 0.19\% del total de la población objetivo: empresas prestadoras de servicios en Lima Metropolitana.

Determinación del tamaño de la muestra:

$\mathrm{N}$ : Empresas, cuya sede principal se encuentran en Lima Metropolitana, que tienen como actividad principal la prestación de servicios.

$$
\begin{aligned}
& \mathrm{N}=202,814 \\
& \mathrm{n}=\mathrm{Nk}^{2} \mathrm{pq}^{2} \\
& (\mathrm{~N}-1)+\mathrm{k}^{2} \mathrm{p} \mathrm{q}
\end{aligned}
$$

Dónde:

$\mathrm{K}: \quad$ Es igual a 1.96 para un nivel de confianza del $95 \%$

p: $\quad$ Proporción de empresas de servicios que utilizan instrumentos de Capital Intelectual.

e: $\quad$ Error muestral del 5\%

Luego remplazando en la fórmula obtenemos:

$$
\begin{gathered}
\mathrm{n}=\frac{(202814)(1.96)^{2}(0.5)(0.5)}{(0.05)^{2}(202814)+(1.96)^{2}(0.5)(0.5)} \\
\mathrm{n}=\frac{194782.5656}{507.035+0.9604} \\
\mathrm{n}=\frac{194782.5656}{507.9954} \\
\mathrm{n}=384.43 \approx 384
\end{gathered}
$$

Luego el tamaño de muestra es igual a 384 empresas.

\section{Técnicas e instrumentos de investigación}

Las técnicas de investigación utilizadas son:

a) Las técnicas de análisis documental

b) Textos de consulta, revistas y artículos sobre Capital Intelectual.

c) La técnica de la encuesta (cuestionarios)

d) Técnica de procesamiento de datos después de aplicar el instrumento, y los reportes de salida para tabular y procesar los resultados de los cuestionarios.

e) Técnica del software SPSS versión 20, para procesar y contrastar hipótesis.

\section{Instrumentos de recolección de datos}

Las técnicas de recolección han permitido recolectar datos pertinentes para abordar el tema de investigación. Los instrumentos utilizados facilitaron la obtención de información para hacer estimaciones que nos permiten conseguir los objetivos de esta tesis.

En toda investigación, una de las etapas más interesantes es la recolección de información, considerando que esta permitirá el desarrollo de los objetivos propuestos por el investigador. El cuestionario contiene las preguntas respecto a la caracterización de la muestra. 
El cuestionario se aplicó a los ejecutivos de la muestra seleccionada a través de entrevista personal o mediante el envío del mismo por correo electrónico, de acuerdo a la accesibilidad que mostraba cada organización para responder acerca del mismo. En todos los casos se incluyó una carta de presentación acerca del trabajo y/o acerca del encuestador ya sea por medio físico o virtual.

Pruebas de análisis de validez y confiabilidad de los instrumentos. En el análisis se tomaran en cuenta los datos obtenidos en la aplicación de los instrumentos, los cuales serán analizados minuciosamente e interpretados con mucho criterio para relacionarlo con los objetivos planteados y explicar los resultados de manera clara, lógica y pertinente.

Para el procesamiento de datos se utiliza el programa SPSS, versión 22.0 con el que se calcula la estadística descriptiva: estadígrafos de tendencia central (media aritmética, mediana y moda) y de dispersión (desviación estándar, coeficiente de variación y rango intercuartílico). Para las pruebas de hipótesis de la existencia o no de la relación entre las variables de estudio se utiliza la prueba de Chi-cuadrado de Pearson x2

\section{Resultados}

Los resultados de la investigación, obtenidos a través de la aplicación de los instrumentos, se muestran detalladamente a continuación.

\section{Prueba de hipótesis}

Nuestro modelo teórico propone la relación positiva del capital intelectual en los resultados empresariales.

\section{Hipótesis principal. Metodologías - Capital Intelectual}

La hipótesis principal plantea la vinculación entre las metodologías aplicadas para evaluar el capital intelectual y la contabilización y por ende la presentación como activo intangible en los Estados Financieros.

Indudablemente que la naturaleza de intangibles de los componentes del capital intelectual presentan una complicación al momento de valuarlos, y siendo la contabilidad prioritariamente cuantitativa, afrontamos el problema de la cuantificación para determinar su aporte y presentación de los estados financieros de la empresa.

Como sostiene Polar (2003), existen dos dificultades para registrar los intangibles en la contabilidad financiera: La identificabilidad, referida a la identificación de los beneficios que se deriven de éstos y la posibilidad de ejercer control sobre los beneficios que estos intangibles generen. Por lo general, no es posible distinguir los costos incurridos para la generación de los intangibles, por lo que resulta difícil medir objetivamente el valor de los mismos. En este sentido sugiere superar las limitaciones inherentes al sistema contable mediante el uso de información no financiera (extracontable) que les permita conocer mejor la situación de la empresa. 
Nevado (2000), indica que nos hallamos ante un escenario contable complejo en valoración. Partimos de la realidad de una diferencia entre el valor de un empresa desde el punto de vista del mercado y el de los libros, es decir, lo que podemos definir como valor extracontable de una empresa.

Arango y otros (2010), sostienen que la diferencia entre el valor de mercado y valor contable es una medida que puede llevar a valoraciones erradas, ya que ambos valores pueden verse afectados por factores externos, principalmente la volatilidad del mercado. Podría considerarse una comparación con sus competidores o con el promedio del sector. Por esta razón, en el cuestionario, que es la herramienta de recolección de datos más utilizada, averiguamos sobre el modelo que utilizan y cómo reflejan los activos intangibles las empresas de servicios encuestadas.

\section{Hipótesis secundaria1. Capital Humano - Capital Intelectual}

Esta hipótesis propone una relación entre el Capital Humano y sus competencias, se expresa en el anunciado: "Si se determina en cuánto influye en el capital intelectual. Entonces se verán resultados sus competencias en las empresas de servicios".

El capital humano constituye el conjunto de recursos intangibles, que incluye habilidades, educación, experiencia, valores. Estudios recientes sugieren que estos atributos de los empleados y directivos, afectan positivamente los resultados de la empresa. Muchas veces estos atributos se deben desarrollar internamente en la empresa, mediante el aprendizaje en el puesto y la formación. El capital humano es necesario para el desarrollo eficiente del trabajo, el Know-how de las personas permite a las empresas obtener ventajas ante la competencia, ejemplo, la disminución de costos de producción y lo más importante que pueden ser fuente de innovación.

Podemos asegurar que, el capital humano es un recurso estratégico y potencial para toda empresa, es escaso, difícil de imitar, transferir, sustituir y pude tener una vida prolongada que si se sabe conservar.

\section{Hipótesis secundaria 2. Capital Estructural - Capital Intelectual}

En esta hipótesis se plantea la relación entre el capital estructural de la empresa, incluyéndose los sistemas de información, y el capital Intelectual.

El capital estructural son "aquellas tecnologías, metodologías y procesos que hacen posible el funcionamiento de la organización, es decir, básicamente, los elementos que definen la forma de trabajo de la organización (Brooking, 1997). Se refiere a la capacidad organizativa de la empresa para satisfacer las demandas del mercado.

No basta con contar con personal capacitado, pues las personas necesitan medios adecuados para desarrollar su labor, como hardware, sistemas de información, infraestructura adecuada, modelos organizativos, procesos de producción. Lo que me permite afirmar que el 
capital estructural son aquellos activos que representan la plataforma que facilitan el trabajo eficiente y eficaz de los recursos humanos de la empresa.

El capital estructural es de propiedad de la empresa, pues pasa a formar parte de su bagaje cultural, de sus idiosincrasia, permanece en la organización, aun cuando las personas la abandonen (Sullivan, 2001). Resulta difícil de sustituir, pues construir capital estructural que facilite el éxito empresarial generalmente lleva un tiempo considerable y esto se convierte en una limitación para la competencia si pretende imitarla, lo que hace aún más difícil su transferencia.

\section{Hipótesis secundaria 3. Capital relacional - Capital intelectual}

La tercera hipótesis secundaria afirma que las buenas relaciones de las empresas de servicios con sus clientes, influyen en la formación de alianzas estratégicas.

Los grupos de interés o stakeholders, son grupos específicos de personas - accionistas, trabajadores, consumidores, comunidad, etc. A los que afectan de una u otra manera las acciones y decisiones de una empresa. Es decir, los stakeholders son aquellos que tienen algún interés legal, ecológico, económico, cultural, etc. - en las operaciones y decisiones de la empresa. (Schwalb, 2004)

El capital relacional se refiere a todas las relaciones que la empresa mantiene con todos los agentes de su entorno. Cuando mayor es el rango que se cubre, favorece a la empresa en la ampliación de su mercado. En general, cuando el entorno específico se caracterice por un elevado grado de rivalidad sectorial, la importancia del mismo será mayor (De la Fuente y otros, 1997).

De acuerdo a Hall (1992) las relaciones de negocio (networks) ocupan el quinto lugar en la lista de los 13 activos intangibles más importantes en el éxito de las empresas. Hay que considerar que las relaciones toman su tiempo en construirlas, más aún en conservarlas y difíciles de recuperar si se pierden. No se pueden comprar, sin embargo, se pueden dañar con mucha facilidad.

La reputación de una empresa es uno de los intangibles más valiosos, incluye una serie de atributos como la calidad de la dirección, calidad de los productos y servicios, innovación, solidez financiera. Las relaciones con los agentes del entorno, implican un conocimiento profundo de los mismos. Contar con información profunda de los clientes, proveedores, comunidad en general, es de un valor incalculable para la empresa, pues ayuda a la creación de nuevos productos y servicios. La confianza que pueden tener los clientes, proveedores, aliados, etc., de la empresa no se puede comparar, se va construyendo a través de una historia de tratos honestos.

\section{Análisis de la información}

Distribución de la muestra de acuerdo al giro de la empresa: De acuerdo a la muestra seleccionada, la distribución según el giro de la empresa es la siguiente:

Tabla 4. Distribución de la muestra de acuerdo al giro de la empresa 


\begin{tabular}{llll}
\hline Giro de la Empresa & Frecuencia & Porcentaje & $\begin{array}{l}\text { Porcentaje } \\
\text { Acumulado }\end{array}$ \\
\hline Servicios de Construcción & 51 & $13.3 \%$ & $13.3 \%$ \\
Servicios Turísticos & 48 & $12.5 \%$ & $25.8 \%$ \\
Servicios Informáticos & 39 & $10.2 \%$ & $35.9 \%$ \\
Retail & 34 & $8.9 \%$ & $44.8 \%$ \\
Banca y Finanzas & 33 & $8.6 \%$ & $53.4 \%$ \\
Restaurantes & 33 & $8.6 \%$ & $62.0 \%$ \\
Servicios de Manufactura & 29 & $7.6 \%$ & $69.5 \%$ \\
Servicios de Salud & 28 & $7.3 \%$ & $76.8 \%$ \\
Servicios de Laboratorio & 12 & $3.1 \%$ & $79.9 \%$ \\
Telecomunicaciones & 12 & $3.1 \%$ & $83.1 \%$ \\
Aerolínea Comercial & 11 & $2.9 \%$ & $85.9 \%$ \\
Investigación de Mercados & 11 & $2.9 \%$ & $88.8 \%$ \\
Servicios de Fotocopiado & 11 & $2.9 \%$ & $91.7 \%$ \\
Textil & 11 & $2.9 \%$ & $94.5 \%$ \\
Casinos & 6 & $1.6 \%$ & $96.1 \%$ \\
Farmacia & 5 & $1.3 \%$ & $97.4 \%$ \\
Gobierno Local & 5 & $1.3 \%$ & $98.7 \%$ \\
Municipalidades & 5 & $1.3 \%$ & $100.0 \%$ \\
Total & 384 & $100 \%$ & \\
\hline
\end{tabular}

Fuente: Elaboración propia.

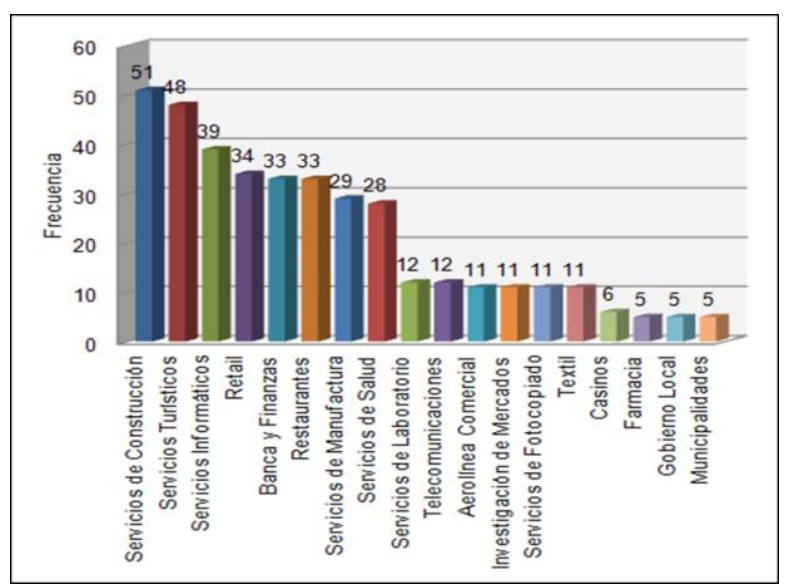

Figura 7. Distribución de frecuencias del giro de la empresa Fuente: Elaboración propia.

Como podemos observar el $13.3 \%$ de las empresas encuestadas pertenecen al sector de Servicios de Construcción, seguidas de Servicios Turísticos (12.5\%), Servicios Informáticos (10.2\%), Retail (8.9\%), Banca y Finanzas y Restaurantes (ambos con el 8.6\%), Servicios de 
Manufactura (7.6\%), Servicios de Salud (7.3\%), Servicios de Laboratorio y Telecomunicaciones (ambos con 3.1\%), Aerolíneas Comerciales, Investigación de Mercados, Servicios de Fotocopiado y Textil (todas con el 2.9\%), Casinos (1.6\%), Farmacia, Gobierno Local y Municipalidades (todas con el 1.3\%).

Distribución de la muestra de acuerdo al sexo: De acuerdo a la muestra seleccionada, la distribución según el sexo de la persona que contestó la encuesta es la siguiente:

Tabla 5. Distribución de la muestra de acuerdo al sexo

\begin{tabular}{lll}
\hline Sexo & Frecuencia & Porcentaje \\
\hline Masculino & 183 & $70.1 \%$ \\
Femenino & 78 & $29.9 \%$ \\
Total & $\mathbf{2 6 1 *}$ & $\mathbf{1 0 0 \%}$ \\
\hline
\end{tabular}

Fuente: Elaboración propia.

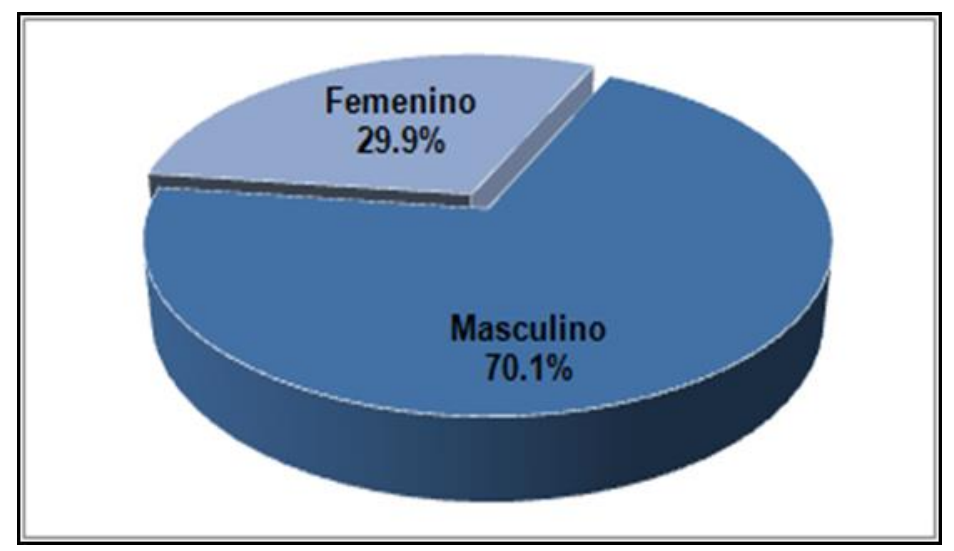

Figura 8. Distribución porcentual del sexo del entrevistado Fuente: Elaboración propia.

Como podemos observar el $70.1 \%$ de las personas que fueron entrevistadas y a las cuales se registró esta variable, corresponden al sexo masculino mientras que el $29.9 \%$ restante corresponden al sexo femenino.

\section{Conocimiento del capital intelectual:}

Respecto al conocimiento del capital intelectual dentro de las empresas entrevistadas, se ha obtenido los siguientes resultados:

\begin{tabular}{|c|c|c|}
\hline Respuesta & Frecuencia & Porcentaje \\
\hline $\mathrm{Si}$ & 373 & $97.1 \%$ \\
\hline No & 11 & $2.9 \%$ \\
\hline Total & 384 & $100 \%$ \\
\hline
\end{tabular}




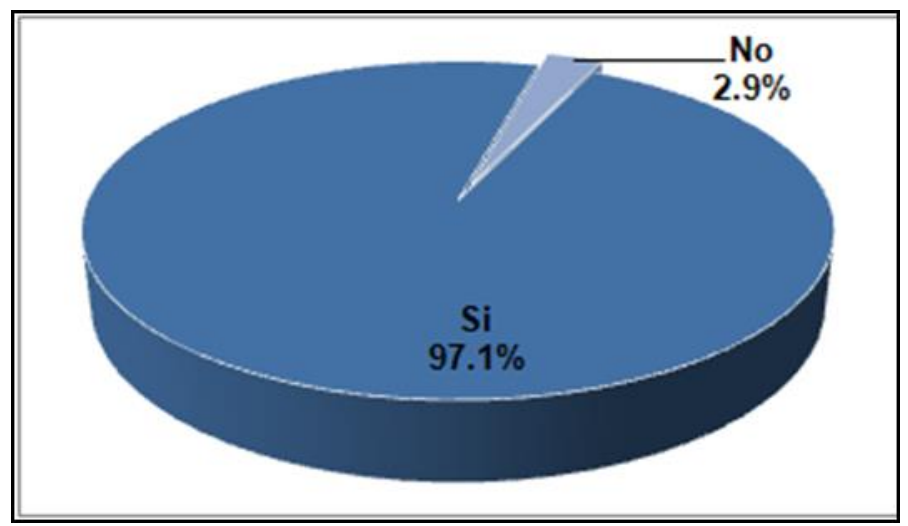

Figura 9. Distribución porcentual del conocimiento acerca del capital intelectual. Fuente: Elaboración propia.

Como podemos observar el $97.1 \%$ de las personas que fueron entrevistadas afirmaron conocer lo que es el Capital Intelectual, contra un $2.9 \%$ que negaron conocerlo.

Uso de instrumentos de capital intelectual:

Respecto al uso de instrumentos del Capital Intelectual en las empresas, dentro de aquellos entrevistados que aseguraron conocer el concepto de Capital Intelectual, se ha obtenido los siguientes resultados:

\begin{tabular}{|c|c|c|}
\hline Respuesta & Frecuencia & Porcentaje \\
\hline $\mathrm{Si}$ & 247 & $66.2 \%$ \\
\hline No & 126 & $33.8 \%$ \\
\hline Total & $373 *$ & $100 \%$ \\
\hline
\end{tabular}

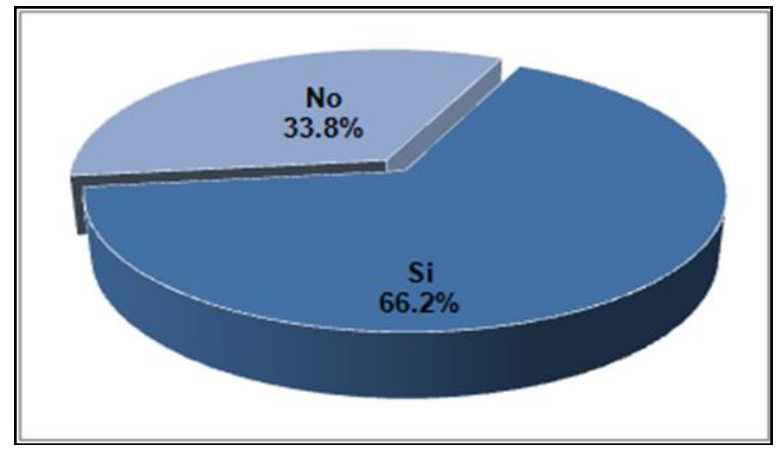

Figura 10. Distribución porcentual del uso de instrumentos de capital intelectual Fuente: Elaboración propia.

Como podemos observar, de los que afirmaron conocer el concepto de Capital Intelectual, el $66.2 \%$ afirmó que en su organización se utiliza un Instrumento de Capital Intelectual vs. El $33.8 \%$ que negó que lo utilizaba. 


\section{Modelo de capital intelectual utilizado:}

Respecto a la pregunta que se les formuló a aquellos que afirmaron utilizar un instrumento de capital intelectual respecto al tipo de modelo utilizado, se ha obtenido los siguientes resultados:

\begin{tabular}{lll} 
Tabla 8. Modelo de capital intelectual utilizado \\
\hline Respuesta & Frecuencia & Porcentaje \\
\hline Balanced Scorecard & 242 & $98.0 \%$ \\
Otro & 5 & $2.0 \%$ \\
Total & $\mathbf{2 4 7} *$ & $\mathbf{1 0 0 \%}$ \\
\hline
\end{tabular}

Fuente: Elaboración propia.

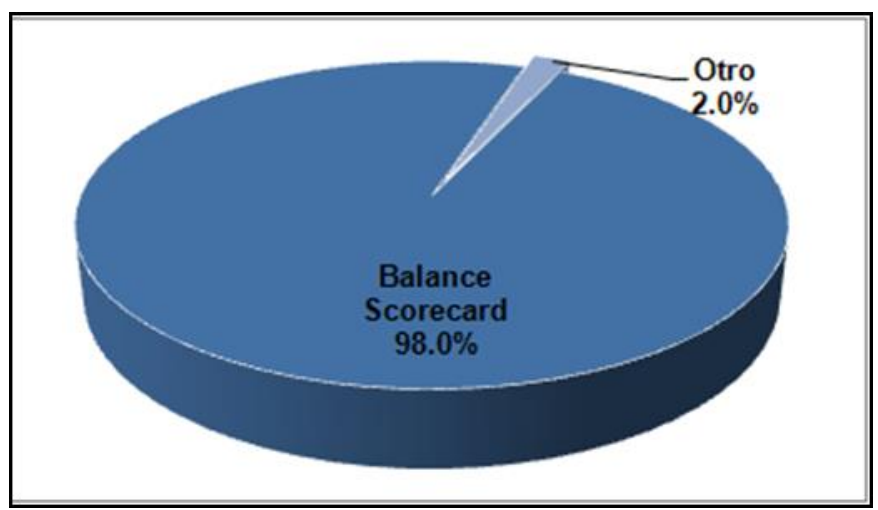

Figura 11. Distribución porcentual del modelo de capital intelectual utilizado Fuente: Elaboración propia.

Como podemos observar, dentro de los que afirmaron utilizar un instrumento de capital intelectual, el 98\% afirmó utilizar el Balanced Scorecard como modelo de Capital Intelectual vs. El 2\% que afirmó utilizar otro tipo de modelo.

Partida presupuestal para investigación y desarrollo:

Respecto a la pregunta si la organización cuenta con alguna partida presupuestal para la investigación y desarrollo de sus actividades, se ha obtenido los siguientes resultados:

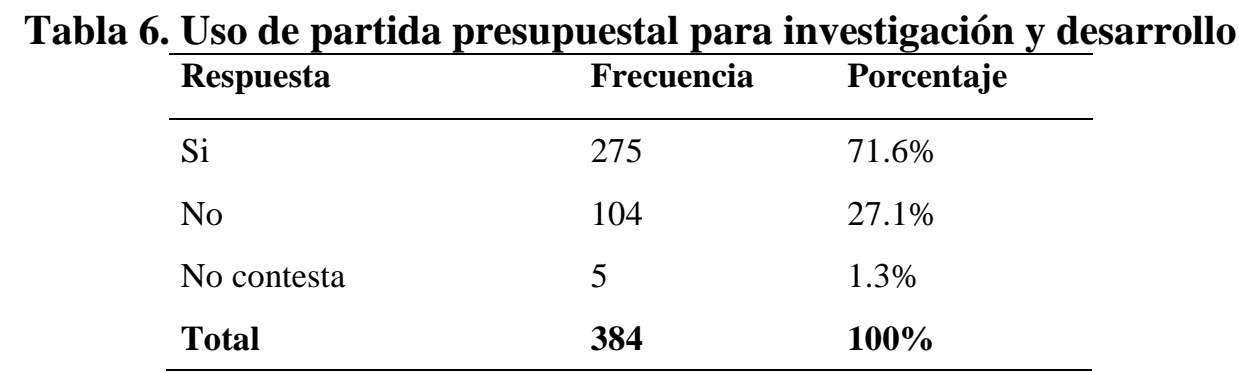

Fuente: Elaboración propia. 


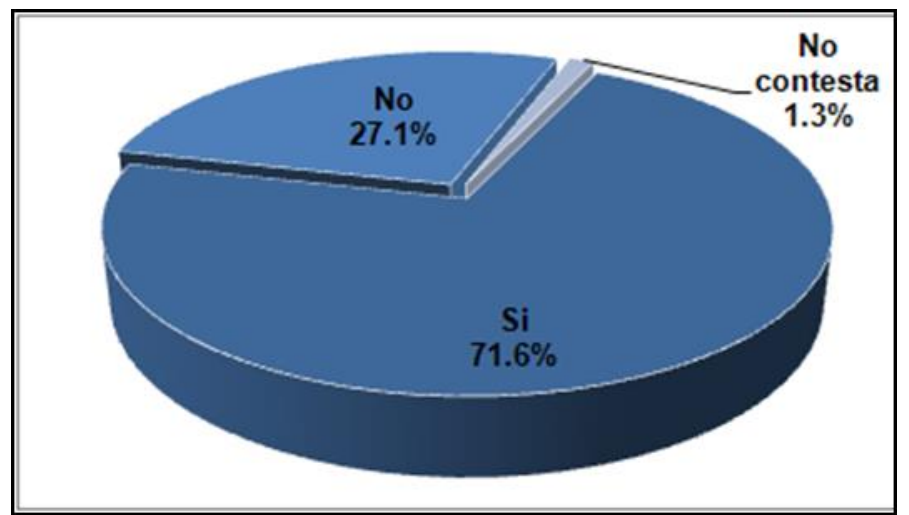

Figura 12. Distribución porcentual del uso de partida presupuestal

Para investigación y desarrollo

Fuente: Elaboración propia.

Como podemos observar el $71.6 \%$ de los entrevistados afirmó que su empresa contaba con una partida para la investigación y desarrollo, mientras que el $27.1 \%$ negó que contara con esta. El $1.3 \%$ de los entrevistados no contestó a esta pregunta.

\section{Tabla 7. Tabla cruzada establecimiento de alianzas estratégicas vs. Acciones para retener} clientes

\begin{tabular}{|c|c|c|c|c|c|c|}
\hline \multirow{2}{*}{$\begin{array}{l}\text { Tabla } \\
\text { Cruzada }\end{array}$} & \multicolumn{5}{|c|}{ Realiza acciones para retener sus clientes } & \multirow[t]{2}{*}{ Total } \\
\hline & Respuesta & $\begin{array}{l}\text { En } \\
\text { desacuerdo }\end{array}$ & Indeciso & $\begin{array}{l}\text { De } \\
\text { acuerdo }\end{array}$ & $\begin{array}{l}\text { Totalmente } \\
\text { de acuerdo }\end{array}$ & \\
\hline \multirow{5}{*}{$\begin{array}{l}\text { Se preocupa la } \\
\text { organización } \\
\text { por establecer } \\
\text { alianzas } \\
\text { estratégicas }\end{array}$} & $\begin{array}{l}\text { Totalmente en } \\
\text { desacuerdo }\end{array}$ & 6 & 0 & 0 & 0 & 6 \\
\hline & En desacuerdo & 0 & 0 & 12 & 0 & 12 \\
\hline & Indeciso & 0 & 11 & 34 & 0 & 45 \\
\hline & De acuerdo & 0 & 5 & 78 & 80 & 163 \\
\hline & $\begin{array}{l}\text { Totalmente de } \\
\text { acuerdo }\end{array}$ & 0 & 0 & 55 & 103 & 158 \\
\hline Total & Total & 6 & 16 & 179 & 183 & 384 \\
\hline
\end{tabular}

Fuente: Elaboración propia.

Tabla 8. Prueba chi cuadrado

\begin{tabular}{cccc}
\hline & Valor & $\begin{array}{c}\text { Grados de } \\
\text { libertad }\end{array}$ & $\begin{array}{c}\text { Sig. asintótica } \\
\text { (bilateral) }\end{array}$ \\
\hline Chi-cuadrado de Pearson & $493.496 \mathrm{a}$ & 12 & 0.000 \\
Razón de verosimilitudes & 178.144 & 12 & 0.000 \\
Asociación lineal por lineal & 120.427 & 1 & 0.000 \\
Nro. de casos válidos & 384 & & \\
\hline
\end{tabular}

a. 10 casillas $(50.0 \%)$ tienen una frecuencia esperada inferior a 5 . La frecuencia mínima esperada es .09.

Fuente: Elaboración propia. 
Como podemos observar, aplicando la prueba Chi-cuadrado, vemos que existe una relación significativa entre el establecimiento de alianzas estratégicas y las acciones para retener clientes de parte de la organización con un $95 \%$ de confianza.

\section{Conclusiones}

La valuación del capital intelectual genera valor para las empresas, mediante el reconocimiento, contabilización y presentación como activo intangible en los estados financieros.

El $97.1 \%$ de las empresas entrevistadas conocen y valoran el concepto de capital intelectual, realizando prácticas encaminadas al establecimiento del mismo, aunque no cuentan con instrumentos para su control y registro.

La mayor parte de empresas le da gran importancia al capital humano, contando con una inversión en temas de capacitación o adiestramiento, contando con herramientas y prácticas de aprendizaje. Valoran el trabajo en equipo, la creatividad, iniciativa, emprendimiento, la formación académica de los empleados, la capacidad de análisis y resolución de problemas. Esto permite que los empleados tengan un fuerte compromiso hacia la organización, apertura al cambio, participen activamente en los cursos y apliquen los conocimientos que han adquirido en las capacitaciones.

Respecto al capital estructural la mayor parte de empresas busca certificaciones, mejoras en los sistemas productivos, competitividad y promueve los círculos de calidad. Poseen inversiones en sistemas aplicando tecnologías de vanguardia como plataformas de información a clientes y mantenimiento de las mismas. Existe descripción de los puestos de trabajo y sistemas de comunicación con sus empleados fomentando un adecuado clima laboral.

Respecto al capital relacional se observa que poseen acciones encaminadas a retener a sus clientes como mecanismos de recolección de opinión, estrategias de valor agregado y acciones para recuperar carteras de clientes. Se ejecutan acciones de seguimiento a la competencia, de colaboración y solidez en las relaciones con los competidores. Poseen eficiente manejo de proveedores contando con una amplia gama de los mismos, los cuales tienen buena capacidad de respuesta ante el mercado. Se preocupan en establecer alianzas estratégicas con diferentes sectores y en su conservación y renovación. Existe relación significativa entre el establecimiento de alianzas estratégicas y acciones para retener clientes.

\section{Bibliografía}

Arango Serna, Martín; Molina Parra, Paula. Zapata Cortés, Julián. (2010). Revisión de metodologías para la valoración del capital intelectual organizacional. Revista virtual Universidad Católica del Norte. Colombia.

Bernal Torres, César. (2000). Metodología de la Investigación. Editorial Pearson Educación de Colombia Ltda.., Colombia 
Brooking, A. (1997): El Capital Intelectual. El principal activo de las Empresas del tercer milenio", Paidós Ibérica S.A. Barcelona.

Bueno, E. (2003): Modelo Intellectus; Medición y Gestión del Capital Intelectual. CIC-IADE, Madrid.

Caballero Romero, Alejandro: (1990) Metodología de la Investigación Científica. Editorial Técnico Científica S.A, Perú.

Castañeda Jiménez, Juan. (2000). Métodos de Investigación II.Edit. McGraw-Hill. Interamericana de México. S.A., México, 2000.

De la Fuentes, J. García Tenorio, J. Guerras, L., y Herman Gómez, J. (1997): Diseño Organizativo de la Empresa, Civitas, Madrid

Edvinsson, Leif y Malone M. (1999).El Capital Intelectual. Editorial Norma. Bogotá.

Elgegren Apuela, José (2005), La Gerencia del conocimiento para optimizar la calidad profesional de los oficiales alumnos de la escuela de infantería del ejercito

Enciclopedia del empresario. (2001). España. Pp 317.

Grant, R. (1996): Dirección Estratégica, Conceptos, Técnicas y aplicaciones, Civitas, Madrid.

Hall, R. (1996): Organizaciones, Estructura, Procesos y Resultados, Prentice Hall Hispanoamericana, S.A. México.

Horngren Charles T. (1995). Contabilidad administrativa. Editorial Prentice may Internacional. Quinta edición. Colombia.

Horngren Charles, Sundem Gary, Elliott John. (2000). Contabilidad Financiera. Prentice Hall Hispanoamericana. México.

Housel, Thomas y Kanevsky, Valery. "Knowledge Value Added (KVA) Methodology"

En: Seminario Internacional: Cómo gestionar la innovación de la empresa y la universidad (2008: Medellín) Corporación Tecnova. 2008. Pp. 1-32.

Juran, J.M., y Gryna, F.M., (1995). Análisis y Planeación de la calidad; Mc. Graw Hill, México.

Kaplan, R., y Norton, D. (1993): Evaluación de los resultados: Algo más que números, Harvard Deusto Business Review, Vol. 55, pp.18-25

Lester R. Bittel y Jackson E. Ramsey (2005).Enciclopedia del management. Océano/Centrum. Barcelona. España. Pp. 1127-1128

Linch Richard M. y Williamson Robert W. (1994). Contabilidad para laGerencia. Planeación y control. Editorial Continental. México. 
López, J. (1996): Los Recursos Intangibles en la Competitividad de las Empresas. Un análisis de la Teoría de los Recursos, Economía Industrial, № 307, pp. 25-35.

Mitchel, Jack. (2004). Abrace a sus clientes. Grupo Editorial Norma. Bogotá.

Navas, J.E., y Guerras, L. (2007): La Dirección Estratégica de la Empresa. Teoría y Aplicaciones, Civitas, tercera edición. Madrid.

Nevado Peña, Domingo. (2000).Cómo medir el capital intelectual de una empresa?

Revista: Partida doble. La mancha.

Polar Falcón, Ernesto. (2002). Aplicaciones técnicas y científicas del capital intellectual en el actual proceso contable del Perú. Revista Quipukamayoc. Lima.

Ralph S. Polimeni, Frank J. Fabozzi, Arthur H. Adelberg, y Michael A. Kole. Contabilidad de Costos. Conceptosy aplicaciones para la toma de decisiones gerenciales. Editorial Mc Graw Hill. Tercera edición.

Rodríguez Porras, José M. (2001). El factor humano en la empresa. Ediciones DEUSTO. Bilboa.

Schwalb María Matilde. (2004), La responsabilidad social: Fundamentos para la competitividad empresarial y el desarrollo sostenible. Universidad del Pacífico. Lima.

Schein, Edgar H. (2000). Psicología Organizacional, Prentice-Hall.

Stoner, James; Freeman, Edward; Gilbert, Daniel. (2005). Administración. Pearson Educación. 10ma. Edición. México.

Sullivan, P. (2001). Rentabilizar el Capital Intelectual. Técnicas para optimizar el valor de la innovación. Paidó Ibérica S.A. Barcelona.

Sveiby, K. (1998): “Intellectual Capital. Thinking Ahead”, Australian CPA, Vol.68, pp. 18-21

Warren Carls S., Reeve James M., Fess Philio E. (2006).Contabilidad Financiera, 7ma.

Edición. Thomson Learning. México. Pp. 398-399.

Gestiopolis (2008) Capital intelectual. Origen, evaluación y desarrollo. Consultado el 25 de febrero 2012. www.gestiopolis.com/economia/capital-intelectual.htm 